\title{
Increasing Community Capacity to Respond to Dementing Illnesses: Process Evaluation of the Community Outreach Education Program
}

\author{
Cathleen M Connell \\ University of Michigan \\ Sara L. Kole \\ Stanford University
}

\begin{abstract}
The goal of the Community Outreach Education Program (COEP) is to disseminate information about the diagnosis, assessment, management, and treatment of dementia to health care professionals, service providers, staff of community organizations and voluntary agencies, and family caregivers in four rural and two urban sites in Michigan. To accomplish this, outreach educational interventions based on a community-development model were developed in the Thumb Area, Upper Peninsula, Northeast Michigan, Mid-Michigan, Detroit, and Flint. The present study describes a process evaluation of the COEP in these six sites, using a multiple case study approach. Shared themes in the successful implementation of the on-site interventions and in creating community capacity across the varied sites are discussed.
\end{abstract}

The Community Outreach Education Program (COEP) was designed to disseminate information about the diagnosis, assessment, management, and

AUTHORS' NOTE: The Community Outreach Education Program is a collaborative effort of the Michigan Alzheimer's Disease Research Center, the Michigan Public Health Institute, and the Alzheimer's Association in Michigan. The authors thank the local coordinators and members of the advisory boards in each site; the executive directors, Michigan Council, and staff of the local chapters of the Alzheimer's Association in Michigan; colleagues at the Michigan Department of Mental Health; and Margaret Allen, Holly Avey, Christopher Benedict, Norman Foster, Sid Gilman, Sara Holmes, Margaret La Pietra, Pegeen McGhan, and Benjamin Walter for their contributions to the project. The authors would also like to thank two anonymous reviewers for their assistance with the final version of this manuscript. This research was supported by grants from the U.S. Public Health Service (NIH NIA No. P50-AG08671 to the Michigan Alzheimer's Disease Research Center and No. R25-AG11219 to the Michigan Public Health Institute) and from the Health Resources and Services Administration (CSH 000148-01-0) to the Michigan Department of Mental Health.

The Journal of Applied Gerontology, Vol. 18 No. 3, September 1999 305-324

(C) 1999 The Southern Gerontological Society 
treatment of dementing illnesses to health care professionals, service providers, staff of community organizations and voluntary agencies, and family caregivers in selected communities throughout Michigan. The long-term objective of the COEP was to create a sustainable impact on the community once the project was completed by fostering a knowledgeable service delivery network with the capacity to respond appropriately to the needs of people with dementing illnesses and their families. The impact of an intervention is sustained when community residents gain knowledge and skills, organizations modify their actions as a result of participating in the project, and interventions are maintained (Altman, 1995; Bracht et al., 1994).

The present study describes a process evaluation of the educational outreach interventions implemented as part of the COEP. Process evaluation complements outcome evaluation by providing data that describe how a program was implemented, to whom services were delivered, how participants and sites responded to the intervention, and the extent to which the target population was reached (Israel et al., 1995; Simons-Morton, Green, \& Gottlieb, 1995). This study builds on previous reports that describe the planning and community assessment phases of the project (Connell et al., 1994; Connell, Kole, Avey, Benedict, \& Gilman, 1996).

\section{Overview of the Process of Implementing the COEP}

The COEP was established as a community-based initiative, built on a partnership between the project team and the community. Such partnerships can facilitate the definition of locally relevant public health issues, the development of culturally appropriate interventions, a sense of project ownership, and the process of creating sustainable community change (Altman, 1995; Freudenberg et al., 1995; Steckler, Dawson, Israel, \& Eng, 1993). Because community-based approaches have the potential to reach large numbers of people, particularly populations that have been underserved, they represent an important strategy for health education interventions (Clark \& McLeroy, 1995; Marin et al., 1995).

The COEP project team included two full-time health educators trained at the master's level in public health with expertise in community-based approaches to outreach education. These two team members were responsible for conducting a comprehensive community assessment at each site, establishing local advisory boards, fostering networking and communication, designing program curriculum, and implementing the onsite interventions. A part-time research assistant developed evaluation materials, transcribed and analyzed data collected during focus group interviews, and coded 
and analyzed data. The project director (and first author) was responsible for overseeing the program, supervising the project team, and preparing reports and manuscripts. Primary funding for the COEP was provided by a grant from the National Institute on Aging designed to support community outreach education programs as part of existing Alzheimer's Disease Research Centers. The COEP was conducted in collaboration with the Michigan Alzheimer's Disease Research Center at the University of Michigan in Ann Arbor. Supplemental funding for the COEP was provided by the Health Resources and Services Administration via a grant to the Michigan Department of Mental Health.

As a first step, local advisory boards were established at each of the six sites involved in the project. The advisory boards consisted of health care professionals, dementia service providers, and representatives of community and voluntary agencies that address the needs of people with dementia. The boards served as community-based coalitions, defined as "a group of individuals representing diverse organizations, factions, or constituencies who agree to work together in order to achieve a common goal" (Butterfoss, Goodman, \& Wandersman, 1993). In addition to providing ongoing leadership for the project, the advisory boards coordinated publicity and local arrangements for the educational interventions and collaborated in all aspects of the program.

In collaboration with the local advisory boards, the COEP team conducted a dementia-specific community assessment to identify community resources and strengths, gaps in service availability, and strategies to increase coordination and communication among service providers. Data were collected via focus group interviews with service providers, physicians, and family caregivers in each of the intervention sites. In addition, representatives of the dementia service delivery networks from each site completed a mailed survey prior to the development of the program.

During a meeting with each local advisory board, the COEP team summarized the community assessment data in a slide presentation and distributed a written report. The report presented the focus group interview data, organized by themes and subthemes, which were illustrated by quotes from the interview transcripts. Survey results were also summarized as part of the report. Specifically, graphs and charts illustrated the availability of local dementia services, perceived obstacles to obtaining services, referral sources for people with memory loss, and demographic profiles of the people with memory loss served by local agencies.

In addition to increasing awareness of local needs and resources, it was hoped that sharing the community assessment data would begin the process of transferring ownership of the program to the local advisory boards. As a 
result of these meetings, priorities for the intervention were established. After the content and the format of the intervention was agreed on, the COEP team and advisory boards worked collaboratively to plan, implement, and evaluate the on-site educational programs.

\section{Process Evaluation-Overview}

The COEP team prepared a detailed case study report that summarized the community assessment, planning, and implementation phase of the outreach educational interventions in each of the six sites. The reports were based on field observations and notes, program records, group discussions, curriculum materials, agendas, minutes of advisory board meetings, program announcements and brochures, and results of exit interviews with program participants and advisory board members. In the process of compiling each site report, the COEP team answered a series of questions corresponding to the process evaluation of the project. Included were questions about how the six catchment areas for the interventions were defined, the composition of the advisory boards, the factors that facilitated and inhibited a sense of community ownership of and involvement in the project, the educational objectives for each component of the intervention, program publicity, target audiences, participation rates, and the extent to which goals and objectives were met. In addition, staff were asked to assess whether the intervention had the potential to have a sustainable impact on the community. Profiles were developed that describe this phase of the project for each of the six intervention sites, including four rural areas (the Thumb Area, Upper Peninsula, Northeast Michigan, and Mid-Michigan) and two urban areas (Detroit and Flint) (see Figure 1 for a map of Michigan that depicts the catchment area for each site). Summaries of each profile are provided next, in chronological order. (For selected demographic characteristics of each of the intervention sites and discussion of the criteria for site selection, see Connell et al., 1994).

Thumb Area. The catchment area for the Thumb Area was defined as Sanilac, Huron, and Tuscola counties (as depicted in Figure 1, this region is referred to as the Thumb Area because it is shaped like the thumb of a hand). This region is the primary service area for the geriatric assessment team associated with the local hospital. The COEP team consulted with members of an advisory board established to guide this geriatric assessment team and decided it was well suited to represent the COEP as well. A local leader and strong advocate for increasing the availability of dementia services at the state level served as the primary COEP contact person in this site. Other 


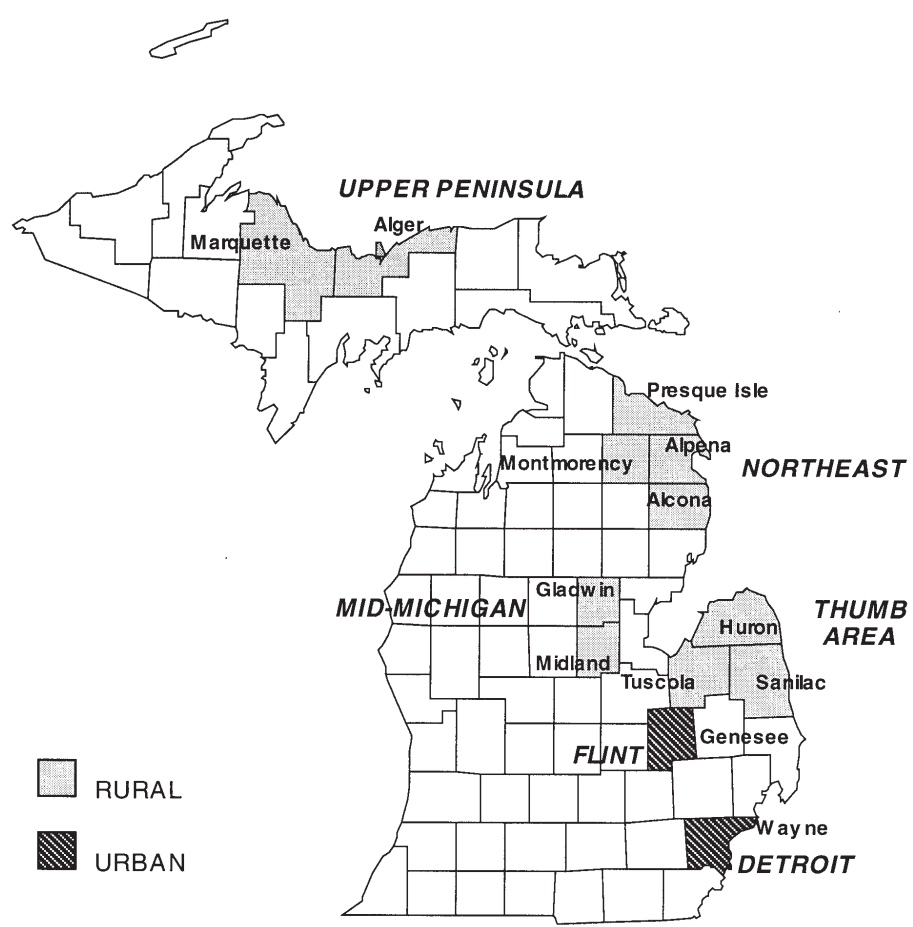

Figure 1. Map of Michigan, depicting intervention sites.

members of the advisory board included staff of the local hospital, home health agency, information and referral agency, county hospital, newspaper, and community mental health agency.

To enhance a sense of community ownership of the project, the first advisory board meeting was devoted to gaining members' input about local goals and priorities and how to accomplish them via the COEP. After an initial presentation about the overall philosophy of and community development approach to the project, initial plans for the community assessment were developed. Specifically, four focus group interviews were conducted with family caregivers and two were conducted with service providers. Because of the difficulty of scheduling focus group interviews with physicians, the COEP team developed a telephone interview protocol to be used by advisory board members to assess the educational needs of local physicians. 
After the results of the community assessment were shared with the advisory board, priorities for the intervention were identified, including providing dementia training for local information and referral staff and increasing knowledge and awareness of dementia among the public, service providers, and health professionals. Work groups, including publicity and promotion, local arrangements, and curriculum development, were established to facilitate implementation of the intervention.

After a number of meetings of the COEP team and local advisory board, the components of the intervention were selected: (a) a community forum featuring exhibits to introduce community residents to the project and local services, (b) an informational session that included an overview of dementia, (c) a session presented by local service providers on managing dementia care in the community and developing linkages among the local service delivery network, (d) a session on research advances, (e) a workshop on effective patient management strategies in home and institutional settings, (f) a training session designed for health professionals to coordinate local autopsy services, and (g) a workshop for local information and referral agency staff to update materials and resources needed to make appropriate referrals.

The publicity and promotion work group developed a program brochure and distributed 3,000 copies with a cover letter to dementia service providers, family caregivers, health care professionals, and community and voluntary agencies. Separate mailings were targeted to local newspapers with a suggested press release and to Thumb Area physicians encouraging their involvement in the program. Radio programs described the project and articles appeared in local newspapers, newsletters, and hospital bulletins.

The community forum, which was open to the public, took place in November 1993. Forty-two people attended. A 1-day program on dementia followed, attended by health professionals, service providers, and family caregivers. In addition, sessions on autopsy, information and referral training, and dementia advocacy were held at appropriate locations in the Thumb Area. The first of three physician programs was scheduled with a local county medical society.

Program planning and implementation was greatly facilitated by the COEP's primary contact person and local leader. A local hospital provided funding to mail the conference brochures and a social service agency coordinated the registration process. Most of the COEP activities took place in a centrally located church. The major obstacle to gaining adequate representation and participation from this site was the geographic distance between the population centers in the three-county region.

Seven groups were specifically targeted by the three days of educational activities: physicians, service providers, information and referral staff, 
professionals responsible for autopsy services, community leaders, community residents, and family caregivers. Each of these groups was reached by one or more components of the program. After the intervention, project staff attended a meeting of the advisory board to share evaluation results and receive further feedback about the intervention. Advisory board members discussed strategies to build on the success of the program, including plans to implement a series of dementia education sessions for local physicians.

Upper Peninsula. The catchment area for the site referred to as the Upper Peninsula was defined as Marquette and Alger counties (see Figure 1). This region comprises the primary service area for the local chapter of the Alzheimer's Association and for an established initiative by the Michigan Department of Mental Health to increase dementia services to this underserved area. An advisory board was in place for this initiative. After consultation with several representatives of the local dementia service delivery network, the COEP team decided that this existing board could also serve in an advisory capacity for the COEP. A staff member of a local service agency served as the primary COEP contact person. Other members of the advisory board included a representative from the local chapter of the Alzheimer's Association, a staff member of a mental health agency, and a neurologist.

During the first meeting with the advisory board, two work groups were established: publicity/promotion and program/curriculum development. As part of the community assessment process, two focus group interviews were conducted with each of three groups: service providers, family caregivers, and primary care physicians. After the results were shared with the advisory board and priorities for the COEP were identified (i.e., increasing public awareness of dementia, increasing knowledge of dementia among physicians and other health care professionals, and responding to the needs of family caregivers), a list of strategies for addressing each priority area was developed. For example, two strategies to increase public awareness of dementia were suggested: (a) a media advocacy session targeted to members of the board of the local chapter of the Alzheimer's Association and (b) a speakers' bureau training for volunteers willing to disseminate information about dementia to interested groups.

Based on meetings of the COEP staff and advisory board, a program that addressed the three identified priority areas was finalized. The various program components were held at multiple sites throughout the catchment area. Dementia training sessions targeting public safety professionals (e.g., local law enforcement personnel, fire safety officials, transit system operators, emergency medical teams) and judges and attorneys were conducted in 
September 1994. The goal of these sessions was to increase awareness of dementia among a diverse group of "front-line" professionals so that they could respond appropriately to people with dementing illnesses. Performers from a local theater company presented a short play that dramatized the conflicts a family faces when a loved one experiences memory loss. The play, written by the COEP team and entitled In Living Memory, ${ }^{1}$ was presented at a local high school. A 1-day speakers' bureau training session was offered to 20 local members of the dementia service delivery network the following day. An educational session for physicians was also presented at a local hospital.

The major event for the Marquette/Alger area was a 1-day program held at a conference facility in September 1994. Approximately 175 service providers and family caregivers attended. The program included an overview of dementia, a panel discussion led by representatives of the local service delivery network, a session on dementia research, a presentation on the managing difficult behaviors, and a discussion led by a group of family caregivers. Concurrent sessions addressed behavior management, therapeutic activities, environmental design, and advance planning, legal, and financial issues. Staff of the Michigan Alzheimer's Disease Research Center (MADRC), dementia consultants hired by the COEP, and local health professionals were responsible for selected components of the curriculum. Finally, the COEP team offered training sessions for pathologists and volunteers willing to assist families with the process of planning an autopsy.

Three factors enhanced the implementation of the program. First, the local advisory board identified community resources and contributed to all aspects of the program. Second, the program coincided with the annual fund-raising event sponsored by the National Alzheimer's Association-Alzheimer's Awareness Week. Finally, local hospitals and the local television cable company contributed to publicity and promotion. Barriers to program implementation are also noteworthy. A training session scheduled for the geriatric assessment team of a local hospital was canceled due to a nursing strike. Another factor was that travel time to the primary intervention site from the home base of the COEP team in southeastern Michigan was an 8-hour trip (see Figure 1). The typically severe winter weather in the Upper Peninsula posed a barrier to planning meetings as well.

The target audience for the week of activities planned as part of the COEP intervention in the Upper Peninsula included health care professionals, service providers, staff of community organizations and voluntary agencies, and family caregivers. Each of these groups was reached by at least one component of the program. Two factors suggested that the program had a positive short-term impact on the community. In the weeks following the program, advisory board members reported an increase in referrals to adult day care 
and respite programs and community interest in volunteerism related to dementia. Speakers' bureau volunteers responded to 15 requests from community groups for presentations about dementia.

Several months after the program, the COEP team met with the advisory board to present evaluation data and discuss next steps. An additional training session for the speakers' bureau was planned, and the board applied for funding to conduct educational outreach programs for local clergy members, a target audience identified during the community assessment. The local chapter of the Alzheimer's Association planned training sessions for support group facilitators and physicians and a follow-up session on autopsy.

Northeast Michigan. The catchment area for the site referred to as Northeast Michigan was defined as Alpena, Alcona, Presque Isle, and Montmorency counties (see Figure 1). The members of the advisory board were recruited at the local level specifically to implement the COEP and included staff from community and social service agencies as well as the local chapter of the Alzheimer's Association. The advisory board was cohesive and well connected in the community. The primary contact person provided leadership and direction for the intervention.

As part of the community assessment, focus group interviews were conducted with service providers, family caregivers, and primary care physicians. Data from these interviews were analyzed and shared during the second meeting of the advisory board. Four priorities were identified: (a) improving information and referral services, (b) increasing public awareness of dementia, (c) increasing knowledge about dementia among professional and family caregivers and physicians, and (d) establishing a diagnostic and assessment team.

As in the other sites, several work groups were established: publicity and promotion, local arrangements, curriculum, and community forum. Next, a list of suggested strategies for addressing each priority area was generated. Program planning continued from January to October 1994. A variety of programs was designed to address the four identified priority areas. The Alpena Area Alzheimer's Awareness Week, as it was named by advisory board members, began with a speakers' bureau training session conducted by the COEP team in collaboration with the local Alzheimer's Association chapter. Approximately 100 people attended an evening community forum about Alzheimer's disease. Participants met local service providers, community leaders, and the project team. The major event was the Alpena Area Alzheimer's Awareness Conference, attended by 140 service providers and caregivers. The opening event featured a presentation by a local nonprofit theater group of In Living Memory. Specific educational sessions followed, 
including (a) an overview of dementia, (b) dementia from a family perspective, and (c) legal issues. The second day opened with general sessions that addressed research advances and managing difficult behaviors. Two sets of concurrent sessions addressed (a) management issues for institutional, respite, and home care staff; (b) caregiver stress and coping; (c) activities for people with dementia; (d) adapting the environment; (e) advanced planning and financial issues; and (f) management issues for family caregivers. Staff of the MADRC and local health professionals were responsible for selected components of the program.

Following the conference, 10 local health care professionals convened to explore options for developing a local diagnostic and assessment team. Later that day, 17 physicians attended a continuing medical education (CME) program on dementia in Alpena. The program featured both didactic and interactive components that addressed the diagnosis and assessment of dementia, research advances, and ethical issues.

Several factors contributed to the successful implementation of the programs, including the ability of the advisory board to reach key target groups and the extensive efforts devoted to publicity and promotion. For example, program activities were covered by local television stations and newspapers; COEP brochures were mailed to more than 1,000 service providers, family caregivers, and community leaders; targeted letters and brochures were sent to more than 100 physicians; and formal invitations to the evening community forum were sent to more than 200 community leaders and physicians. Each of the four priorities outlined by the advisory board were addressed as part of the educational programs. Project staff scheduled a follow-up meeting with the advisory board in February 1995 to review evaluation materials and feedback. Advisory board members reported an increase in the number of calls to the local information and referral agency and expanded awareness among physicians of local dementia services. Advisory board members also expressed their continued commitment to establishing a geriatric assessment clinic.

Mid-Michigan. The catchment area for the Mid-Michigan site was defined as Midland and Gladwin counties (see Figure 1). The advisory board recruited for the COEP was comprised, in part, of health professionals who had previously organized as an advocacy group for the development of an adult day care program. Members included staff of local social service agencies, the local chapter of the Alzheimer's Association, a regional medical center, and a nursing home.

As part of the community assessment process, three focus group interviews were conducted with family caregivers and two with service providers. 
A summary of the focus group data was shared with the advisory board. Four priorities for the COEP were identified, including (a) increasing knowledge of dementia among professional and family caregivers, (b) improving the response by public safety officials to people with dementia, (c) improving local information and referral services, and (d) advocating for innovative adult day care and other respite care programs. The target audience for the educational program was defined as family and professional caregivers. Because the distance between the two counties included in the catchment area was thought to be a barrier to participation, a similar program targeted exclusively to family caregivers was planned for Gladwin county. To target physicians, separate CME programs were planned for the two counties. More than 1,000 brochures describing the program were distributed to local dementia service providers, health professionals, and family caregivers. In addition, articles in local newsletters were published and press releases were distributed to local newspapers and radio stations.

Program planning was accomplished during 10 meetings of the advisory board and the COEP team. Four work groups were established: publicity and promotion, curriculum development, local arrangements, and community events. The Midland program was held at a hotel in April 1995 and was attended by 154 service providers and family caregivers. The final program included a session on research issues presented by staff of the MADRC and concurrent workshops led by dementia consultants that addressed the management of problem behavior and legal and financial issues. Thirty-six family caregivers attended a similar program in Gladwin. In addition, 40 physicians attended a separately scheduled CME program in Midland. In Gladwin County, a similar program was held for 10 physicians. The play In Living Memory was performed by a local theater group at the beginning of each program. Each of the target audiences-family and professional caregivers, service providers, and physicians-participated in some aspect of the program. The COEP team met with members of the advisory board to review evaluation materials and feedback from participants.

The advisory board continues to serve in an advocacy role to increase awareness of dementia, coordinate existing dementia services, and develop new services. Dementia training sessions for public safety officials were held in both counties several months after the completion of the program. These sessions represent an important step in the transfer of the project to the community because they were planned by the advisory board with minimal input from the COEP team.

Detroit. The catchment area for this site included the Detroit metropolitan area (see Figure 1), served by a local chapter of the Alzheimer's Association. 
A staff member of the chapter served as the primary contact person for the COEP and greatly influenced the direction and scope of the program. On her suggestion, the six physicians who served on the Medical and Scientific Advisory Board of the local chapter were asked to serve in the advisory role for the COEP.

The COEP staff encountered a number of obstacles in transferring ownership of the project. Gaining commitment to and investment in the program was especially challenging due to the composition of the advisory group and their demanding schedules as physicians. In contrast to the advisory boards in the other sites, this group was involved in the organizational and community development aspects of the project in a limited way. Initially, the local coordinator was concerned that the project not duplicate services or programs already being implemented by the local chapter. Because physician education was a top priority for the chapter and was supported by the local leader and advisory board, this area became the primary focus of the COEP activities at this site.

Four priorities for intervention were identified: (a) the assessment and diagnosis of dementing illnesses, (b) research and treatment issues, (c) community resources, and (d) ethical and cultural issues related to caregiving. A primary objective was to design the educational sessions so that physicians could readily integrate the knowledge they gained into their practices. In addition, strategies to maximize participation among culturally and ethnically diverse groups were developed, including selecting a downtown rather than a suburban location for the program and distributing promotion materials to minority physicians.

Advisory board members generated a variety of suggestions for publicity and promotion that were implemented by the COEP team: (a) approximately 4,000 program announcements were distributed 2 months prior to the program to local physicians in the Detroit metropolitan area, using membership lists of regional medical societies, including 500 African American physicians in the Detroit area; (b) approximately 4,000 program brochures were distributed 6 weeks prior to the program, using the same mailing list; (c) more than 100 confirmation cards were sent to physicians who registered for the program in advance; and (d) newsletter articles and press releases appeared in state and county medical society publications, the Alzheimer's Association monthly newsletter, and several local newspapers. Incentives were offered to increase attendance, including offering CME credits for participation.

Planning for the program was accomplished over the course of 10 advisory board meetings held over a 1-year period. The program was held in May 1995 in downtown Detroit and was attended by 82 participants, including physicians, nurses, and local service providers. The final program included a 
keynote address by a nationally recognized dementia expert. Other sessions included (a) a panel presentation by local service providers to increase awareness of community resources; (b) a discussion of racial, ethnic, and cultural differences in dementia caregiving presented by local experts of African American, Hispanic, and Arab American descent; and (c) a seminar on driving and safety issues. The day's events concluded with dinner and a presentation on ethical issues related to the assessment, diagnosis, care, and treatment of dementia.

Factors that influenced the success of the program included the support of the local chapter of the Alzheimer's Association and the advisory group of respected physicians that represented the five major medical institutions in the Detroit area. Other contributors to program success included the CME credit offered, the convenient location of the conference hotel, and the national reputation of the presenters. Although only eight African Americans attended (including five physicians), outreach to the Detroit Medical Society was helpful in building collaborative ties for future educational activities.

In addition, indicators of program success are noteworthy. The conference was well received as determined by the participants' evaluations. As a result of the session on community resources, physicians became aware of the services provided by the Detroit chapter of the Alzheimer's Association.

Flint. The catchment area for the final site was defined as Genesee County, which includes Flint and the surrounding area (see Figure 1). One of the goals for the COEP program in Flint was to provide educational outreach to ethnic minority and underserved communities. This focus was consistent with the goals of the local chapter of the Alzheimer's Association, which was a key collaborator at this site. Members of the advisory board included a geriatrician, social worker, and staff of local health and social services agencies.

One of the first challenges to the planning phase of the COEP in Flint was involving representatives from the three local hospital systems and the wide variety of dementia service providers. Initially, members of the COEP team were viewed as outsiders and as competitors rather than collaborators in a mutually beneficial community development process. Because this perspective served as a barrier to coordinated dementia care, developing strategies for cooperation and shared problem solving was critical. During the first two meetings of the advisory board, COEP staff facilitated open discussion about the goals and expectations for the program. This process facilitated a sense of group accomplishment and helped to define a common vision for the program. Another issue that confronted the COEP staff was the challenge inherent in defining a single "community" within a culturally and ethnically diverse area. This issue was made more difficult because the initial 
formulation of the advisory board was not representative of the intended target audience, broadly defined as the underserved. The COEP addressed this problem by actively recruiting additional advisory board members from agencies that served primarily minority clients. Their efforts were successful, particularly in the recruitment of a community organizer who was knowledgeable about issues related to dementia faced by clergy and congregation members in the African American church.

Two focus group interviews were conducted, one with family caregivers and one with service providers. The data were shared with the advisory board and were particularly useful in documenting how important attending church can be for older adults and how memory loss can interfere with this experience. As a result of this meeting, the advisory board decided to build on the strengths and resources of local churches. Specifically, a dementia training session for ethnically and culturally diverse clergy and lay leaders was developed using a "train the trainer" approach. Other program objectives included (a) offering a training session for public safety officials, (b) offering a presentation on dementia for ethnically and culturally diverse family care and primary care physicians, and (c) disseminating information about dementia to culturally diverse communities. In retrospect, an additional component of the community assessment should have been conducted after the decision was made to target the program to the needs of clergy members. Focus group interviews with members of local congregations and clergy members would have been extremely helpful in planning the major portion of the program in Flint.

The COEP staff met with the advisory board 15 times over a 1 -year period to plan a 1-day program in June 1995 at a local church. The program, entitled "Forget Me Not, Forsake Me Not: Ministry of Love for Memory Loss," included the following sessions: (a) an overview of how faith communities can address the needs of congregation members with memory loss, presented by a local community organizer; (b) a performance of In Living Memory by a local theater group; (c) an overview of dementia presented by a local neurologist; and (d) small group discussions focusing on presenting information about dementia to congregations and community groups, helping caregivers cope with memory loss, and assisting families with financial and legal planning.

Publicity for the program was extensive and included a mailing to more than 700 religious leaders and organizations in the Flint area. Churches promoted the program in their weekly bulletins, and information about the program appeared in the local newspaper and on the radio. A follow-up postcard was sent to local pastors 2 weeks before the program to remind them of the date, location, and time of the program. Finally, two advisory board members 
recruited volunteers to contact clergy members by telephone the week before the program to encourage their attendance. Implementation of the program was facilitated by the endorsement of local churches and African American clergy members. Attendance at the 1-day event, held in a local church, was 97. The majority of program participants were ordained or lay leaders and interested congregation members. Thus, the goal to target clergy and lay leaders and increase awareness of dementia in faith communities was met.

Follow-up telephone interviews were conducted with 25 participants to assess the impact of the program. Participants reported that they would provide counseling for affected family members and outreach to congregation members in long-term care facilities. A number of follow-up activities were implemented. African American church team members of a local community organization performed their own version of In Living Memory for approximately 100 nurses attending a local conference. A local church offered a presentation entitled "The Ten Warning Signs of Alzheimer's Disease" to their congregation.

By being involved in the planning and implementation of the program, the local chapter of the Alzheimer's Association targeted its outreach to ethnically diverse communities and built a foundation to expand these efforts. One of the community organizations that participated in the program was asked to provide dementia training to area churches. In addition, training sessions for public safety officials were conducted in September 1995. These sessions were arranged primarily by the advisory board members in Flint, with relatively little input from the COEP team.

\section{Implications for Practitioners}

Several implications for practitioners can be drawn from the process of planning and implementing the community-based educational interventions. A local coordinator, well connected in the community, who provided leadership and was committed to the goals of the COEP, was vital to the success of the program in each of the six sites. The sooner that this person was identified, the better. In four of the six sites, local coordinators emerged very early in the community development process and facilitated the transfer of ownership of the project to the local level. In two sites, the process of securing ownership of and active involvement in the project was much slower and COEP staff assumed responsibility for tasks that were best accomplished by community residents. Ideally, the availability of a highly committed local coordinator should be a criterion for site selection for this type of collaborative educational outreach program. 
The importance of striking a balance between following a precise "road map" that guides the community development process and being responsive to unique circumstances in each site cannot be overstated. The COEP team conducted a dementia-specific community assessment in each site prior to the design of the educational interventions. A specific protocol was used to guide this process, including a mailed survey and structured focus group interviews (as described in Connell et al., 1996). Although this data collection strategy provided valuable information, it would have been preferable to target the community assessment more specifically in some sites. In Flint, for example, clergy members were not included in the community assessment because it was planned before the advisory board decided how the program would be targeted. Ideally, clergy members would have played an integral part in all phases of program planning. Although using the same framework to conduct the six community assessments made it possible to compare and contrast the data collected among sites, a targeted approach may have been more valuable for program planning. A combination of a standard framework for part of the community assessment (to facilitate comparisons) with a more targeted approach is recommended. In addition, advisory board members should be involved in all phases of the community assessment process to assure that the data collected is locally relevant and can be used to inform follow-up activities after the funding period ends.

In three sites, an existing advisory group convened to address local dementia issues was recruited to serve in a similar capacity for the COEP. A major advantage of relying on an existing board was that the COEP team was able to involve the community in the program as soon as contact with the site had been initiated. The greatest disadvantage was the challenge of making the COEP a top priority among the boards' other activities. An advisory board was created specifically for the COEP in three sites. Obviously, the process of identifying members and developing group cohesion was slower than in those sites with an established advisory board. When these boards were finally in place, however, they were particularly well suited to accomplishing the goals of the COEP because members with expertise relevant to the program goals were identified and recruited.

The success of any planned change effort depends on the effectiveness of the interpersonal relationships established between the project staff and the program participants (Israel et al., 1995). For all of the sites, the COEP team found it valuable to address group process issues within the advisory boards. For example, having individual members identify their goals, expectations, and roles related to the COEP enhanced a sense of commitment to the project. Encouraging advisory board members to invest community resources in the 
COEP (e.g., publicity and promotion) increased a sense of involvement in the project and satisfaction with its rewards.

Each of the six interventions was designed and implemented over the course of a 3-year grant period. Project staff worked with each community an average of 10 months prior to the implementation of the on-site educational program. This relatively short time frame proved to be challenging, given the distance between sites and the need to allow each community sufficient time to conduct an assessment, establish priority areas, and plan and implement locally relevant educational programs. In addition, the COEP team soon realized that fall and spring were the only mutually agreeable times to conduct the educational interventions due to the number of community residents who are on vacation during the summer and the travel constraints posed by Michigan winters. Whenever practical, trips to multiple sites were combined.

One of the advantages of conducting multiple interventions simultaneously is that educational materials can be shared among sites and attempts can be made to replicate the success of various components of the program. For example, the play depicting a family coping with dementia was so successful in the Upper Peninsula that local theater groups planned similar activities in three other sites. The establishment of work groups within the advisory boards was so effective in the first intervention site that similar groups were established in subsequent sites.

After the community assessment data were shared with the advisory boards, each site formulated specific educational objectives for their local intervention. Across the six sites, the objectives were quite similar. For example, increasing public awareness of dementing illnesses was a top priority in the Thumb Area, Upper Peninsula, and Northeast Michigan. Improving local information and referral services was a focus of the interventions planned for the Thumb Area, Northeast Michigan, and Mid-Michigan. Dementia training sessions were completed with a variety of target audiences, including physicians (in five sites), family caregivers (five sites), service providers (four sites), public safety officials (three sites), community residents (two sites), information and referral staff (one site), and clergy members (one site). Outreach to culturally diverse groups was a priority in the two urban areas, including members of the clergy and physicians.

Several intervention components implemented across the six sites were particularly effective in increasing community capacity. For example, the dementia training sessions that were based on a train-the-trainer model offer great potential for a sustainable impact. In each site, a cadre of individuals with diverse areas of expertise is now able to respond to the needs of people with dementing illnesses and continue to work toward program goals, even after the COEP has officially ended. In addition, community residents in 
several sites formed advocacy groups to increase the availability of specific dementia services in their area. Because the play In Living Memory is presented by local theater groups, it has the potential to increase knowledge and awareness of dementia long after the COEP project period. Finally, the community forums designed to link the local service delivery networks were particularly effective in improving the response to people with dementia by increasing coordination and communication among local providers. Other components of the COEP interventions, although successful, have less potential to increase community capacity. For example, the CME programs and 1-day conferences offered as part of the COEP provided an efficient way of disseminating information to large audiences but are less likely to result in long-term change at the community level.

Because families often turn to their primary care physicians for information about dementing illnesses, they represent an important target audience for community-based outreach programs. Outreach programs are particularly appropriate because many physicians are uninformed about dementia (Fortinsky, Leighton, \& Wasson, 1995; Rubin, Glasser, \& Werckle, 1987) and unaware of dementia services in their communities (Haley, Clair, \& Saulsberry, 1993). Based on the experiences of the COEP, physicians were the most difficult group to involve in the community-based programs. Even in Detroit, where the entire program was devoted to physician education, only one-half of the program participants were physicians. To the extent possible, physicians should be included in all phases of outreach activities, including the community assessment and planning phases, so that their input can be maximized and potential barriers to participation can be addressed. Key informant interviews, conducted at a convenient location suggested by the physician, may be a particularly appropriate way to solicit input.

Dementia outreach usually entails the dissemination of basic information about Alzheimer's disease and related disorders to physicians, nurses, social workers, and staff of long-term care facilities. Although this approach is valuable and has the potential to reach relatively large and appropriate target audiences, community involvement is generally limited and the long-term impact of such programs is rarely assessed. The COEP, in contrast, relied on information gathered during a collaborative community assessment to inform an educational program that addressed issues of local concern. Community residents were involved in all phases of program planning, design, implementation, and evaluation. Although this approach requires a significant amount of personnel effort and diverse community resources, one of its greatest advantages is that it has the potential to strengthen the capacity of communities to respond appropriately to the needs of people with dementing illnesses and their families and to have a sustainable impact. In each of the six 
intervention sites, the advisory boards continue to plan educational activities, serve as advocates for the development of new dementia services, and collaborate with other local, state, and national agencies in the continuation of their goals.

\section{Note}

1. For a copy of the play, contact the Alzheimer's Disease Education and Referral Center (ADEAR) at 1-800-438-4380. ADEAR, established in 1990, is a service of the National Institute on Aging.

\section{References}

Altman, D. G. (1995). Sustaining interventions in community systems: On the relationship between researchers and communities. Health Psychology, 14(6), 526-536.

Bracht, N., Finnegan, J. R., Rissel, C., Weisbrod, R., Gleason, J., Corbett, J., \& VeblenMortenson, S. (1994). Community ownership and program continuation following a health demonstration project. Health Education Research: Theory and Practice, 9(2), 243-255.

Butterfoss, F. D., Goodman, R. M., \& Wandersman, A. (1993). Community coalitions for prevention and health promotion. Health Education Research: Theory and Practice, 8(3), 315-330.

Clark, N. M., \& McLeroy, K. R. (1995). Creating capacity through health education: What we know and what we don't. Health Education Quarterly, 22(3), 273-289.

Connell, C. M, Kole, S. L., Avey, H., Benedict, C. J., \& Gilman, S. (1996). Attitudes about Alzheimer's disease and the dementia service delivery network among family caregivers and service providers in rural Michigan. American Journal of Alzheimer's Disease, 11 (3), 15-25.

Connell, C. M, Kole, S. L., Benedict, C. J., Holmes, S. B., Gilman, S., \& Beane, G. E. (1994). Increasing coordination of the dementia service delivery network: Planning for the Community Outreach Education Program. The Gerontologist, 34(5), 700-706.

Fortinsky, R. H., Leighton, A., \& Wasson, J. H. (1995). Primary care physician's diagnostic, management and referral practices for older persons and families affected by dementia. Research on Aging, 17(2), 124-148.

Freudenberg, N., Eng, E., Flay, B., Parcel, G., Rogers, T., \& Wallerstein, N. (1995). Strengthening individual and community capacity to prevent disease and promote health: In search of relevant theories and principles. Health Education Quarterly, 22(3), 290-306.

Haley, W. E., Clair, J. M., \& Saulsberry, K. (1993). Family caregiver satisfaction with medical care of their demented relatives. The Gerontologist, 32(2), 219-226.

Israel, B. A., Cummings, K. M., Dignan, M. B., Heaney, C. A., Perales, D. P., Simons-Morton, B. G., \& Zimmerman, M. A. (1995). Evaluation of health education programs: Current assessment and future directions. Health Education Quarterly, 22(3), 364-389.

Marin, G., Burhansstipanov, L., Connell, C. M, Gielen, A. C., Helitzer-Allen, D., Lorig, K., Morisky, D. E., Tenney, M., \& Thomas, S. (1995). A research agenda for health education among underserved populations. Health Education Quarterly, 22(3), 346-363. 
Rubin, S. M., Glasser, J. L., \& Werckle, M. A. (1987). The examination of physician's awareness of dementing disorders. Journal of the American Geriatrics Society, 35(12), 1051-1058.

Simons-Morton, B. G., Green, W. A., \& Gottlieb, N. (1995). Health education and health promotion (2nd ed.). Prospect Heights, IL: Waveland.

Steckler, A., Dawson, L., Israel, B., \& Eng, E. (1993). Community health development: An overview of the works of Guy W. Steuart. Health Education Quarterly, Supplement 1, S3-S20.

Article accepted June 10, 1998

Cathleen M Connell, Ph.D., is an associate professor in the Department of Health Behavior and Health Education in the School of Public Health at the University of Michigan. She completed her doctoral training in human development and family studies at Pennsylvania State University. Her research focuses primarily on the psychosocial context of chronic illness among older adults. Recent publications include "Older Adults in Health Education Research: Some Recommendations" in Health Education Research: Theory and Practice (in press) and "Racial, Ethnic, and Cultural Differences in Dementia Caregiving: Review and Analysis" (with R. Gibson) in The Gerontologist (1997).

Sara L. Kole, MPH, is a field coordinator with the Stanford Center for Research in Disease Prevention in Palo Alto, California. She coordinates a community-based research project: Teen Activists for Community Change and Leadership Education. She holds a master's degree in public health and a bachelor's degree in political science from the University of Michigan. Her research interests include community-based chronic illness prevention/intervention. Previous publications include "Increasing Coordination of the Dementia Service Delivery Network: Planning for the Community Outreach and Education Program" (with C. M Connell, C. J. Benedict, S. B. Holmes, S. Gilman, and E. Beane) in The Gerontologist (1994). 